\title{
Creating of a Personal Labor Motivation System
}

\author{
Irina Vaslavskaya \\ Department of Economics \\ Kazan Federal University \\ Naberezhnye Chelny, Russia \\ vaslavskaya@yandex.ru \\ Chulpan Ziganshina \\ Department of Philology \\ Kazan Federal University \\ Naberezhnye Chelny, Russia
}

\author{
Albina Bilyalova \\ Department of Philology \\ Kazan Federal University \\ Naberezhnye Chelny, Russia \\ abill71@mail.ru \\ Inna Murtazina \\ Department of Economics \\ Kazan Federal University \\ Naberezhnye Chelny, Russia \\ inna4386@mail.ru
}

\begin{abstract}
The article analyzes several theories of staff motivation. It was concluded that various theories of motivation basically do not contradict each other, but complement each other, reflecting the versatility and originality of the motivation process itself.

The relevance of the work is associated with the understanding that effective staff motivation is one of the most significant factors in the competitiveness of modern organizations. The article shows that the staff motivation system is based on the formation of the employees' production behavior aimed at achieving strategic objectives, that is, combining the interests and needs of employees with the strategic objectives of the enterprise.

The authors express the opinion that motive and stimulus are not synonyms; an equal sign between these concepts should not be put. They conclude that the main goal of the development and functioning of the personnel motivation and incentive system is to ensure the achievement of the goals of the enterprise with the involvement and retention of professionally trained personnel. In this case, motivation is an effective, powerful and sustainable way, formed on the basis of complex incentives.
\end{abstract}

Keywords: stimulus, motivation, needs, substantive theories of motivation, procedural theories of motivation

\section{INTRODUCTION}

Despite the variety of terms and definitions existing in the scientific literature, there is still no consensus and a clear statement of the concepts "motive" and "motivation". It is worth noting that experts in the economic field, scientific sociologists and psychologists study and consider the categories of motivation from different angles. Some see motivation as an encouragement of labor, that is, they put an equal sign between these concepts, while others, on the contrary, contrast these two categories. There is also another point of view, the essence of which is that stimulation is the main and priority method of motivation.

Motivation has many different definitions. A large number of studies relate to motivation in education, healthcare, psychology. But in this paper it is important to focus on those that are related to the workplace. Understanding exactly what motivation is will help managers decide what actions to take to encourage their employees. The definition of motivation starts with the root word, motive. Webster's Dictionary defines motive as, something that causes a person to act. Therefore, motivation can be defined as, the act of providing motive that causes someone to act [1]. With relation to the workplace, Ray Williams, who writes for Psychology Today, defines motivation as, "predisposition to behave in a purposeful manner to achieve specific, unmet needs and the will to achieve, and the inner force that drives individuals to accomplish personal organizational goals" [2].

Richard Ryan and Edward Deci, from the University of Rochester, agree that motivated means that the person is moved to do a particular act. The authors describe motivation as, the "orientation of motivation concerns the underlying attitudes and goals that give rise to action" [3].

Despite the variety of terms and definitions existing in the scientific literature, there is still no consensus and no clear statement of the concepts "motive" and "motivation". It is worth noting that experts in the economic field, scientific sociologists and psychologists study and consider the categories of motivation from different angles. Some see motivation as an encouragement of labor, that is, they put an equal sign between these concepts, while others, on the contrary, contrast these two categories. There is also another point of view, the essence of which is that stimulation is the main and priority method of motivation [4]. 


\section{DISCUSSIONS}

"The process of using various incentives to motivate people is called the process of stimulation" [8]. The main goal of stimulating labor is not just to give employees work and make them do it, but to inspire them to conquer new professional heights, increase the working capacity of the team, and make work more efficient and creative, in other words to produce more than it is stipulated in the labor contract. Any manager of the company wants to fulfill this task, and it is feasible, but only with an integrated approach and stimulation of labor [9].

It is worth noting that motivation is based on a multicomponent layer consisting of needs, motives and goals of a person. Let's try to formulate very nominally the main definitions of motivation. Human needs are a special inner state when there is a desire and a need to receive and possess an object. For the comfortable existence of the individual this need must be satisfied. Needs are the moving mechanism of human behavior, they serve as a source of inspiration, become the cause of his enterprising intentions and energetic actions. A motive is an incentive initiative of a person that seeks to achieve a goal. The goal is a wishful object, service or state, to obtain of which a person so aspires [10].

The General scheme of the motivational process, reflecting its cyclicality and versatility, as well as the relationship of needs, motives and goals, is presented in figure 1 .

\section{METHODS}

During the study, the authors used the following methods:

- theoretical ( work with literary sources);

- analytical (analysis of the information collected, drawing conclusions, making recommendations).

\section{RESULTS}

The result of the analysis of modern theories of motivation was the revealed fact that the fundamental fact in motivation is its inseparability and interdependence with human needs.

Today, there is a large number of different theories of personnel motivation, because this problem was and is one of the most urgent. They tried to increase the working capacity of the employee since ancient times, however, most often only penalties were applied. In the modern world, when an employee has the right to choose a type of activity, compare working conditions, corporations are forced to pay due attention to the problems of motivating personnel to perform production tasks, to increase competitiveness in the market of similar goods and services, to retain valuable and highly qualified employees, etc.

It is worth noting that many theories of motivation most often do not go against each other, but are mutually beneficial. In the theories we have examined, one can see the versatility, non-standardness and originality of the motivation process, which implies the need for an integrated approach to solving this complex but interesting issue.

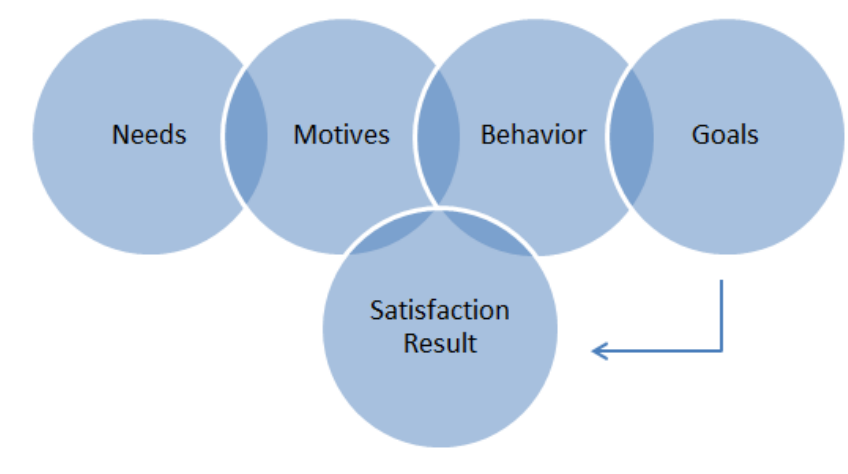

Fig. 1. Scheme of the motivational process

It important to underline that the scheme of the motivational process presented above is very nominal and very simplified. It gives only a small idea of the correlation of needs and motives. The real motivational process of a person can be very confusing, in fact, it seems more complex and multilevel. Motivational processes are very contradictory, prone to change and evolve under the influence of a range of factors (external and internal), such as performance, education, social status, material well-being, public opinion, personal ambitions, intelligence, ingenuity and many others. The set and variety of factors leads to the fact that forecasting the behavior of members of the workforce of the enterprise is a very complex and time-consuming process. Motivation in the enterprise should be considered as a multicomponent matrix, as a set of different incentives. 
The concepts "motivation" and "stimulation" are used not only in the sense of formation of individual, group and collective motives, but also to indicate the process of influence of incentives on motives to obtain the required level of motivation [11].

So, the issues related to the importance of motivation are relevant and very important, so they are given great attention in scientific circles by management theorists. Modern theories of motivation are divided into substantive and procedural. At the heart of meaningful theories are human needs, they are the ones that motivate to act in one way or another. Of course, procedural theories do not discard the fact that the individual acts out of his own and personal motives and to satisfy his needs, but, nevertheless, place the main emphasis on the behavior of people, because take into account factors such as education, knowledge and achievements.

Let's consider the most famous and meaningful theories of motivation relevant to this day. Such are the theories of A. Maslow, F. Herzberg, D. McClelland.

The theories of these scientists can be divided into two groups.:

1) primary - associated with physiological factors;

2) secondary - associated with psychological nature.

Thanks to scientific researches of the American scientist Abraham Maslow we know that it is necessary to satisfy first of all physiological needs of the person. After satisfaction of physiological needs, the need for safety comes to the first place. The human individual always wants to protect himself from any bodily harm and aggressive, deviant behavior of other people. On the next step there is the need for spiritual kinship, relationships, the search for love. Friendships, the search for a niche in social society, interaction with society that is what is necessary to meet the most important needs.

The next new step in the hierarchy of needs is the need for respect and self-esteem. It is crucially important for a person to understand his "I" of his own importance, it is necessary to confirm and recognize self-esteem in the eyes of others. The top of the needs in the pyramid of A. Maslow is the realization of a person in fulfilling his destiny, using all his creative and labor abilities.

It should never be forgot that human needs are modified, transformed and evolve from the simplest to the more complex and ornate. If part of the needs are satisfied at one level, the needs of the next level come to the fore, etc. However, most often there is a basic and dominant need, which is the main and motivating incentive. The main mistake of managers of managers of companies is that most believe that high efficiency depends only on material values. It should be remembered that all people are different and needs can be dramatically different from each other. If a person has a pronounced need for self-realization, then he will definitely choose the job where he can apply his labor skills and nontrivial and creative abilities, and not money [9].

In McClelland's theory of motivation, the need for power and success can be located between the needs for respect and self-expression in Maslow's hierarchical structure. The need to belong to a group corresponds to social needs [12].

American scientist psychologist Frederick Herzberg specialized in the problems of society and in the late 50s of the $\mathrm{XX}$ century formulated his own model of motivation based on needs [13].

In Herzberg's theory motives for work are divided into:

- hygienic factors, they are directly related to the environment in which the work is performed (this includes working conditions and wages and physiological needs of the person);

- factors related to the essence and nature of the work performed, i.e. motivation as such.

Herzberg made the assumption that hygienic factors are not motives, but, if they are not provided, there is a negative attitude to work. To understand the influence of material and non-material factors, the scientific community has sought for many years. And as the result a theory of motivation of $\mathrm{F}$. Herzberg appeared: he created a two-factor model that shows job satisfaction (Table I).

TABLE I. FACTORS AFFECTING JOB SATISFACTION

\begin{tabular}{|l|l|}
\hline \multicolumn{1}{|c|}{ Hygiene factors } & \multicolumn{1}{c|}{ Motivation } \\
\hline Company and administration policy & Success \\
\hline Operation condition & Promotion \\
\hline Earnings & $\begin{array}{l}\text { Recognition and approval of work } \\
\text { results }\end{array}$ \\
\hline Interpersonal relationship & High degree of responsibility \\
\hline Degree of direct control over work & $\begin{array}{l}\text { Opportunity for creative and } \\
\text { business growth }\end{array}$ \\
\hline
\end{tabular}

The first group of factors (hygiene factors) is related to the self-expression of the individual, its internal needs, as well as the environment in which the work itself is carried out. The second group of motivation factors is determined by the nature and essence of the work performed. The head who is responsible for motivation of the personnel at the enterprise should not forget about necessity of generalization of a substantial part of work.

If we compare the theories of Maslow and Herzberg, we can find fundamental differences. A. Maslow suggests that after the application of motivational incentives, the employee necessarily begins to work better and more effectively realize their creative potential. According To F. Herzberg, the employee will work best only after he is convinced that the motivation is adequate.

Let's view the following theory of motivation, the founder of which is Clayton Alderfer. He takes as a basis the assumption that human needs can be divided into separate groups. He considered the needs of a man from different angles and combined them into three main groups, namely, the needs of existence, the needs of communication, the needs of growth [14]. All these three groups of needs are arranged in a hierarchical order, as in the pyramid of needs of A. Maslow, 
but it is worth noting that there is a significant difference between the theories of Maslow and Alderfer. The movement from need to need is carried out only from the bottom up - this is according to Maslow. Alderfer also suggested in his theory that the movement can be carried out in both directions. It is possible to move up if a lower level need is satisfied, and it is assumed to move down if it is not possible to reach a high level of need or to experience satisfaction from a given need. Alderfer gave the name to these movements up and down the levels of needs, so the process of moving up is called the process of satisfaction of needs, and the process of moving down is called the process of frustration

The scientific community, represented by the authors of substantial theories, contributed to the understanding of motivation and its factors. But they could not take into account the many obligations necessary to explain the mechanism of motivation (behavioral aspects, environmental parameters, etc.). Among the many procedural theories of motivation, the most widely accepted are the theory of expectation, the theory of justice and the Porter-Lawler model.

Canadian psychologist Victor Vroom put forward a number of ideas on issues of motivation and created his theory, which is called the theory of expectation. The author suggested that expectation is an assessment of the individual in the probability of a particular event. There are three important interrelated components in expectation theory, namely, labor costs, results (remuneration) and satisfaction with remuneration [15]. The idea of Vroom's theory is that the motivation and satisfaction received by the employee directly depends on how much the expected remuneration corresponds to the results of his work. The employee must have a clear understanding that his work will be fully rewarded, and if a person does not see a clear correlation between the work he has done and the desired reward, the motivation will decrease and go out.

Let's consider the theory of justice, which follows from the theory of expectations. Employees who conscientiously fulfill their labor duties assume that their labor costs will be marked by the management of the company and the remuneration will correspond to their expectations. Employees also compare the remuneration received and the effort expended with the remuneration of colleagues performing similar functions in the enterprise. With a significant imbalance, the identification of injustices in bonuses and the payment of remuneration, the motivation of employees also drops sharply. There are two ways to eliminate the imbalance, namely, to increase remuneration (the way for the company management), to reduce the costs of your labor (a negative way for an employee who sees injustice).

Researchers Lyman Porter and Edward Lawler revealed the correlation between the theory of expectation and the theory of justice, and developed their theory by combining both theories together [16]. The scientific work of Porter Lawler is a more complex theory of motivation, which combines five variables: the effort spent in the process of work, perception, the results of labor activity, remuneration, and, of course, the degree of satisfaction. The basis of this theory is the fact that work efficiency directly depends on the efforts made by the employee, his individual capabilities and abilities, and on the understanding of the importance of the work performed. The effectiveness and level of labor costs of an employee of the company will directly depend on the value of the remuneration and on how confident the employee is in the remuneration stability for the work performed [17].

Also Porter-Lawler's theory has in its content expectation theory, because the employee expects decent encouragement from the company's management and hopes that his remuneration will be consistent with the efforts spent. Elements of the theory of justice also take place and are manifested in the fact that human beings always have their own evaluative opinion regarding fair or unfair compensation in comparison with other employees of the company and the degree of satisfaction. Having considered this theory of motivation, we can draw the following conclusion that labor results are the reason for employee satisfaction, and not vice versa. According to this theory, the productivity of labor must certainly increase [11]. One of the most important conclusions from this model is that productive work leads to satisfaction and contributes to an increase in labor productivity [13].

The scientific works of the famous psychologist of the XX century Berres Skinner made an invaluable contribution to the study of the mechanism of inducing a person to work [18]. The essence of his research, in the field of studying motivation, is that the employee relies on his previous experience to achieve some positive result in the professional field. For example, employees, knowing how to effectively perform certain production tasks, rely on their previous work experience, they also try to evade or move away from those tasks that lead to an undesired result.

Not only the Western scientific community was interested in the study and development of theories of motivation. Our domestic scientists also looked for answers in this field, and L.S. Vygotsky, A.N. Leont'ev, B.F. Lomov achieved maximum success at this matter. Scientists considered the theory of motivation one-sidedly, only from the point of view of psychology: they took pedagogical activity as the basis and did not study production issues, although this theory is suitable for production activity.

Scientists emphasized that the individual makes decisions at the level of regulation, adaptation, self-organization. His needs and requirements are realized at each of these levels simultaneously. It turns out that all human needs (this includes the minimum, higher, and the highest needs) are generated simultaneously and in parallel. A complex and multiple totality of these needs guides the actions of a person, thus, there is a triple nature of satisfying needs through tangible and intangible incentives [19].

A.A. Litvinuk created a complex of motivations that affect the behavior of a person or a work team, and combined them into five groups:

- motives for the acquisition, the natural desire of a person to receive a coveted reward for conscientious work; 
combination with methods of incentives that have already proven themselves in practice, contributes to the creation and implementation of an effective staff motivation system [26].

According to the results of the study, it can be stated that the main goal of the creation and functioning of the system of motivation and stimulation of staff is directly related to ensuring the achievement of the general goals of the enterprise [27].

Thus, formed on the basis of attracting and retaining professionally trained personnel and through effective, powerful and stable motivation on the basis of complex incentives, the motivation system is an object of interest for all groups of company personnel.

\section{REFERENCES}

which has its own structure and depends on the specific labor situation". In his opinion, the motive characterizes the employee's efforts to get certain benefits and the incentive are these benefits themselves. An incentive may not degenerate into a motive if it requires incredible, inaccessible or unacceptable actions from a person. The mechanism of manipulating incentives should be adequate to the mechanism of employee motivation [21].

Recently, around the world, especially in marketdeveloped countries, the process of employee motivation is often undergoing significant changes. So, according to Brian Tracy, the most effective is the combination of material and social incentives [22].

In Turkey, modern managers along with material motivation highlight corporate culture, a high level of working conditions and psychological motivation methods, which together work to increase employee motivation and increase their satisfaction with the company [23].

Recent studies by Malaysian scientists have revealed that the modern needs for motivating staff are not only appropriate working conditions and advanced training, but also the expression of personal opinion by employees regarding the work of the company, their work and the work of colleagues [24].

In our opinion, the ongoing changes in approaches to staff motivation both in Russia and in foreign countries are primarily associated with improving the quality of life of the population, the emergence of new opportunities and priorities 25].

Based on this, to create an effective motivation system, one should choose such a set of approaches that will allow the most effective management of personnel and improve the result of the enterprise.

\section{CONCLUSIONS}

Analysis of existing theories of motivation showed that when creating a motivation system, it is necessary to take into account, first of all, the motivational structure of employees in each group and division of the enterprise. In our opinion, this is what will allow us to stimulate the labor team to initiative and highly productive activities. This approach, in
[1] H. Shanks, Management and Motivation, vol. 2, 2003, pp. 23-35.

[2] Williams, What really motivates us?, 2019, https://raywilliams.ca/what-

[3] R. Ryan, L. Edward, "Intrinsic and Extrinsic Motivations: Classic Definitions and New Directions", Contemporary Educational Psychology 2000, pp. 54-67.

[4] J. Forth, A. Bryson, A. George, "Explaining Cross-National Variation in Workplace Employee Representation", IZA Discussion Papers, 2016, vol. 9963, in press European Journal of Industrial Relations.

[5] N. Mescon, M. Albert, F. Hedouri, Fundamentals of Management, 2002, p. 704.

[6] B.M. Genkin, Economics and sociology of labor: textbook for universities, vol. 7, 2007, p. 448.

[7] P.V. Zhuravlev, S.A. Kartashov, Personnel management technology, 200 , p. 575.

[8] I.P. Stukanova, Management: study guide, 2005, p. 224.

[9] E. Meshcheryakova, A. Tulekbayeva, A. Naukenova, S. Beyseyev, A. Otunshiyeva, "Improvement of human resources management in the system of quality management", Industrial technology and engineering, vol. 4(29), 2018, pp. 46-55.

[10] V.M. Tsvetaev, HR Management, 2002, p. 563.

[11] Yu.N. Bogdanov, Yu.V. Zorin, D.A. Shmonin, V.T. Yarygin, "Personnel Motivation", Quality Management Methods, vol. 11, 2005.

[12] D.C. McClelland, "How motives, skills, and values determine what people do", American Psychologist, vol. 40(7), 1985, p. 812.

[13] F. Herzberg, "Motivation-hygiene theory", Organizational behavior one: Essential theories of motivation and leadership, 2005, pp. 61-74.

[14] C.P. Alderfer, "A critique of Salancik and Pfeffer's examination of need-satisfaction theories", Administrative Science Quarterly, 1977, pp. 658-669.

[15] V.H. Vroom, Work and motivation, 1964.

[16] E.E. Lawler, G. Christopher, G. Worley, Management Reset: Organizing for Sustainable Effectiveness, 2011.

[17] A. Cunyat, "Crowding-out effect and sorting in competitive labor markets with motivated workers", Applied Economics Letters, vol. 26(4), 2019, p. 326-330.

[18] A Review of B.F. Skinner's, 2014, //https://www.researchgate.net/publication/306091479_A_Review_of_B _F_Skinner's_'Reinforcement_Theory_of_Motivation.

[19] S. Gope, G. Elia, G. Ppassiante, "The effect of hrm practices on knowledge management capacity: a comparative study in Indian it industry. Emerald Group Publishing Limited", Journal of knowledge management, 22(3), 2018, p. 649.

[20] A.A. Litvinyuk, Motivational complex of labor activity, 1997.

[21] A.Ya. Kibanov, Personnel Management. Theory and practice. Motivation and stimulation of labor activity, 2017. really-motivates-us-what-science-says/. 
2005 ,

22] B. Tracy,

Leading

\& Motivating, http://www.livingbeyondbetter.com/leadermot.html.

[23] Meryem Aybas, Ahmet Cevat Acar, "The Effect of Human Resource Management Practices on Employees' Work Engagement and the Mediating and Moderating Role of Positive Psychological Capital", International Review of Management and Marketing, vol. 1, 2017, p. 369.

[24] Roselina Ahmad Saufi, Yang Xin, Cheng Hongyun, Siti Aishah Berhan, Abdullah Al Mamu, "The Relationship between Personality Dimensions and Employee Job Commitment in Private Higher Learning Institutions", International Review of Management and Marketing, vol. 7(1), 2017, p. 431
[25] O. Nadirov, K. Aliyev, B. Dehning, "To work more or less? The impact of taxes and life satisfaction on the motivation to work in continental", Economics and Sociology eastern Europe, vol. 10(3), 2017, p. 26.

[26] E. Brand, T. Korner, S. Perrenoud, F. Pintaldi, "Towards a crossnational comparison of quality of employment", An analysis based on data from Finland, Germany, Israel, Italy and Switzerland Statistical Journal of the IAOS, vol. 35(3), 2017, pp. 465-480.

[27] M.D.S. Sabbagha, O. Ledimo, N. Martins, "Predicting staff retention from employee motivation and job satisfaction", Journal of Psychology in Africa, vol. 28(2), 2018, pp. 136-140 